\title{
Resúmenes de Literatura Médica
}

\section{LISTERIOSIS EN LA GESTACION}

JOSE FAGNONI, ARTURO ACHARD y colaboradores. - Reproducción. Vol. I № 1, 1974.

Se presentan los tres primeros casos descritos en el Uruguay de la enfermedad llamada granulomatosis infantil séptica, causada por la listeria monocitógena.

Se hace una revisión histórica de la enfermedad, la cual es una infección bacteriana que se presenta en el hombre y en gran número de animales. El $75 \%$ de los casos publicados en el mundo corresponden a recién nacidos.

Es producida por la Listeria Monocitogenes y se considera una Zoonosis transmisible al hombre y de difusión universal.

Se le ha aislado en mamíferos, aves, peces y crustáceos y se le encuentra en las aguas, cloacas, forrajes, etc.

En el recién nacido se adquiere por infección transplacentaria. En la madre puede transcurrir en forma subclínica o su sintomatología ser muy benigna. En el feto es habitualmente mortal, provocando la muerte in utero o la muerte del recién nacido en la primera semana de vida.

El diagnóstico se hace por el hallazgo de la Listeria en las secreciones del cuello, del útero o la vagina. Se debe investigar siempre en mujeres con aborto habitual, muerte del feto in útero y muertes neonatales de etiología oscura. En el recién nacido se encuentra fácilmente en la sangre, en el meconio y en las heces.

La investigación en casos sospechosos es posible que muestre que la incidencia es grande, ya que como se mencionó es una zoonosis presente en gran variedad de especies animales y de fácil contagio para el hombre.

El diagnóstico serológico se hace por reacciones de seroaglutinación, fijación de complemento $y$ de hemoaglutinación.

El tratamiento específico se hace actualmente a base de ampicilina.

\section{MIGRACION DE LOS ESPERMATOZOIDES EN LA MUJER}

AQUILES SOBRERO. - New York - Reproducción. Vol. I No 1, 1974.

El autor hace un recuento de las características de la migración espermática en la mujer y de algunos hechos nuevos que se supone ocurren desde el momento de la eyaculación hasta la fecundación. En la primera etapa de la espermoemigración, esta se hace por la movilidad intrínseca 
de los espermatozoides los cuales deben penetrar el moco cervical. Llegados a la cavidad uterina permanecen en el fluído intrauterino y su transporte se efectúa de manera pasiva por medio de contracciones miometriales; vuelve a recobrar toda su capacidad de motilidad en el interior de la trompa uterina y cerca al sitio de la fertilización.

El autor describe un sistema de valorización para el moco cervical que contempla cinco variantes de fácil interpretación (cantidad, color, filancia, células y arborización); también describe la clasificación que utiliza para el test post-coital.

Durante el período fértil o preovulatorio, con un moco cervical abundante, claro, y con escasas células se encuentran espermatozoides móviles en el moco cervical 90 segundos después de la eyaculación y en el fluído intrauterino 4 a 5 minutos después de la eyaculación.

Las moléculas glicoproteicas del moco, limitan la migración espermática y se constituyen en una reserva ya que los espermatozoides activos permanecen dentro de las criptas mucosas y van siendo liberados gradualmente para acudir al sitio de la fertilización. También parece operarse en el moco un mecanismo altamente selectivo que elimina las formas anormales y las formas inmóviles de los espermatozoides.

Finalmente se discute la información contradictoria de los posibles efectos de la ocitocina y de las prostaglandinas E1, E2, y E3 en la migración espermática.

\section{BASES FISIOLOGICAS DEL DIAGNOSTICO DE LA OVULACION}

LIDIA M. CARRIL, ALFREDO CASTRO, J. ROSNERR. - San Miguel, Argentina. Reproducción. Vol. I No 1, 1974.

En la primera parte del artículo se analizan los conocimientos actuales de la fisiología del ciclo menstrual y la evaluación de los procedimientos existentes para predecir o detectar la ovulación. Se hace la enumeración de estos procedimientos los cuales son la observación casual de ésta por celioscopia o laparotomía; al determinación de niveles hormonales en sangre y orina de gonadotropinas, y hormonas esteroides; la biopsia de endometrio que informa retrospectivamente sobre la ocurrencia del suceso; las características del moco cervical investigadas por el método de Billings, la presencia de filancia, cristalización, prueba de la bencidina, test de la glucosa; citología funcional, temperatura basal y cambios en la saliva paralelos a los del moco cervical.

Se concluye de que a pesar de que abundan los métodos para predecir o diagnosticar ovulación retrospectivamente ninguno lo hace con certeza y que la determinación de estrógenos plasmáticos se constituyen en el mejor indicador para predecir ovulación varios días antes de que ocurra que el pico de LH es el mejor índice de la inminencia de la ovulación, junto con el moco cervical.

La progesterona plasmática a su vez, es el mejor parámetro para el diagnóstico retrospectivo de la ovulación. El desarrollo de las técnicas de radioinmunoensayo para determinar gonadotropinas y hormonas esteroides, por su precisión y facilidad de realización, permitirán que estas técnicas sean tan accesibles a la práctica ginecológica como lo ha sido hasta ahora la utilización del moco cervical. 